\title{
Substituent effects in hydrogen bonding: DFT and QTAIM studies on acids and carboxylates complexes with formamide
}

\author{
Borys Ośmiałowski
}

Received: 17 April 2014 / Accepted: 15 June 2014 / Published online: 15 July 2014

(C) The Author(s) 2014. This article is published with open access at Springerlink.com

\begin{abstract}
Four series of hydrogen bonded complexes of formamide and substituted benzoic acids and benzoates were studied in the light of substituent effect on intermolecular interactions. The analysis based on energy of interaction, geometry, QTAIM-derived properties of hydrogen bond critical point and energy of hydrogen bonds were made and discussed. The opposite effect of the substituent on hydrogen bond donor and acceptor in acid series was found and analyzed. The isodesmic reactions were used to further study the interaction preferences.
\end{abstract}

Keywords Cooperativity · Hydrogen bonding · QTAIM theory $\cdot$ Substituent effect $\cdot$ Weak interactions

\section{Introduction}

Nowadays hydrogen bonding is used as a force in noncovalent synthesis. This synthesis [1] is focused mostly on crystal engineering [2-4], a non-covalent polymerization [5-7] but hydrogen bonding may be used also in chemical sensing [8-14]. The ability to tune the properties of molecules by changing the substituent comes from the basic research by Hammett [15]. However, in supramolecular chemistry there are several possibilities to tune the non-covalent interactions $[16,17]$. These are the electronic substituent effect [18-20, 17], steric effect [21-24], and intermolecular electronic repulsion [25] to mention a few. Although very good reviews on

Electronic supplementary material The online version of this article (doi:10.1007/s00894-014-2356-8) contains supplementary material, which is available to authorized users.

B. Ośmiałowski $(\square)$

Faculty of Chemical Technology and Engineering, University of

Technology and Life Sciences, Seminaryjna 3,

PL-85-326 Bydgoszcz, Poland

e-mail: borys.osmialowski@utp.edu.pl tuning the molecular properties and thus influence on their interactions has been published there are still not so many extensive works in the topic of pure substituent effect in simple associates. This is especially true for studies taking into account more than five various substituents. Recently it was shown that the association of substituted benzoates with heterocyclic urea derivatives preceded by breaking the intramolecular hydrogen bond is driven by the character of the substituent [18]. In compounds that are able to form a intramolecular hydrogen bond such a conformation is preferred. There are many examples of compounds that behave this way as: heterocyclic ureas [26, 27], enamines or enolimines [28-30] and others including biomolecules [31]. On the other hand the compounds that are not able to form such stabilizing interaction can form various dimers, trimers etc. or their rotamers may be stabilized as various associates. The rotamerism in such molecules may be probed by the use of appropriate hydrogen-bonding counterparts [21]. However in simple, model molecules such rotamerism is not possible or does not influence the association due to the symmetry of the part of the molecule. The rotation about C-N bond in formamide does not change its hydrogen-bonding pattern. Thus this simple model may be a structure of choice [32] to study the interactions of amides with acids and carboxylates taking into account the substituent effect. The carboxylates were used in several studies as anions that probe the non-covalent interactions [19, 33, 34]. The regular substituent-dependent changes in properties of carboxylic acids and thus benzoates are commonly known. The acidity and thus donation ability of the hydrogen bond donor $(\mathrm{OH})$ in - $\mathrm{COOH}$ moiety in acids may be a good test for description of interaction preferences driven by the character of the substituent. On the other hand the basicity and thus the ability of being an acceptor for hydrogen bonds as in phenolates [35-38] of carboxylates [19, 33, 34] may be used in a similar way. In 4-substituted benzoates, however, both oxygen atoms are equal in the light of hydrogen bonding. 
<smiles></smiles>

A<smiles>NC=CCOC(=O)c1ccccc1</smiles>

B

Fig. 1 Three forms of studied formamide complexes

In acids the $-\mathrm{COOH}$ group contains donor and acceptor of the hydrogen bond. Changing the electronic properties of the carboxylic acid influence the properties of $\mathrm{C}=\mathrm{O}$ and $\mathrm{OH}$ groups in opposite ways. These features were taken into account during design of the series of calculations. The aim of this study is to: $a$ ) study the substituent effect on association of the model molecule (formamide), b) check if the weak hydrogen bond by $\mathrm{CH}$ group plays a crucial role in association, $c$ ) compared to the various arrangements of molecules within the complex in light of their interaction and $d$ ) study how the substituent effect influences association when two various species are associated with formamide at a time. In Fig. 1 three forms of associates are shown.

It is worth pointing out that forms $\mathbf{A}, \mathbf{B}$, and $\mathbf{C}$ differ by topology. In form $\mathbf{A}$ the eight-membered ring is stabilized by two hydrogen bonds, while in $\mathbf{B}$ the seven-membered ring is present. In form $\mathbf{C}$ the seven-membered ring is also stabilized by two hydrogen bonds but it differ from $\mathbf{B}$ by $a$ ) net charge and $b$ ) the composition of the quasi-ring with hydrogen bonds. In forms $\mathbf{A}$ and $\mathbf{B}$ both molecules consist of one hydrogen bond acceptor and one donor (assuming $\mathrm{CH} \cdots \mathrm{O}$ weak interaction as a hydrogen bond type of interaction), while in $\mathbf{C}$ both

Table $2 \mathrm{ZPE}$ and BSSE corrected $\mathrm{E}_{\mathrm{int}}\left[\mathrm{kJ} \mathrm{mol}^{-1}\right]$ for the studied complexes

\begin{tabular}{lllll}
\hline $\mathrm{R}$ & $\sigma[46]$ & Form A & Form B & foRm C \\
\hline $\mathrm{NMe}_{2}$ & -0.83 & -37.7 & -28.8 & -40.7 \\
$\mathrm{NH}_{2}$ & -0.66 & -37.9 & -29.2 & -40.3 \\
$\mathrm{OMe}$ & -0.27 & -38.6 & -30.2 & -39.4 \\
$\mathrm{Me}$ & -0.17 & -38.7 & -30.8 & -39.3 \\
$\mathrm{H}$ & 0 & -39.1 & -31.5 & -38.8 \\
$\mathrm{~F}$ & 0.06 & -39.5 & -32.1 & -38.4 \\
$\mathrm{Cl}$ & 0.23 & -39.7 & -32.4 & -38.1 \\
$\mathrm{CF}_{3}$ & 0.54 & -40.3 & -33.5 & -37.6 \\
$\mathrm{NO}_{2}$ & 0.78 & -41.1 & -34.7 & -36.6 \\
$R$ & & 0.991 & 0.994 & 0.994 \\
$a$ & & -2.12 & -3.69 & 2.44 \\
$b$ & & -39.25 & -31.60 & -38.72
\end{tabular}

$R$ - correlation coefficient

acceptors belong to benzoate and both hydrogen bond donors to the formamide.

\section{Computational methods}

All calculations were performed with the use of Gaussian software [39]. The M05 functional suggested for non-covalent interactions [40, 41] was used together with the $6-311+\mathrm{G}(2 \mathrm{~d}, 2 \mathrm{p})$ basis set as in previous publications $[18,21,22]$. The use of the diffuse functions is crucial for describing the anionic specie, while polarization functions are used to properly describe the hydrogen bonding. Optimizations were performed with the use of PCM model of solvation [42] in chloroform since in previous publications such treatment was in

Table 1 The lengths $[\AA]$ of hydrogen bonds in complexes A-C

\begin{tabular}{|c|c|c|c|c|c|c|c|}
\hline \multirow[b]{2}{*}{$\mathrm{R}$} & \multirow[b]{2}{*}{$\sigma[46]$} & \multicolumn{2}{|l|}{ Form $\mathbf{A}$} & \multicolumn{2}{|l|}{ Form $\mathbf{B}$} & \multicolumn{2}{|l|}{ Form $\mathbf{C}$} \\
\hline & & $\mathrm{OH} \cdots \mathrm{O}$ & $\mathrm{NH} \cdots \mathrm{O}$ & $\mathrm{OH} \cdots \mathrm{O}$ & $\mathrm{CH} \cdots \mathrm{O}$ & $\mathrm{CH} \cdots \mathrm{O}$ & $\mathrm{NH} \cdots \mathrm{O}$ \\
\hline $\mathrm{NMe}_{2}$ & -0.83 & 1.739 & 1.919 & 1.732 & 2.454 & 2.662 & 1.798 \\
\hline $\mathrm{NH}_{2}$ & -0.66 & 1.732 & 1.925 & 1.725 & 2.464 & 2.663 & 1.801 \\
\hline $\mathrm{OMe}$ & -0.27 & 1.719 & 1.935 & 1.714 & 2.462 & 2.663 & 1.810 \\
\hline $\mathrm{Me}$ & -0.17 & 1.715 & 1.941 & 1.710 & 2.485 & 2.666 & 1.807 \\
\hline $\mathrm{H}$ & 0.00 & 1.708 & 1.946 & 1.704 & 2.491 & 2.668 & 1.811 \\
\hline $\mathrm{F}$ & 0.06 & 1.703 & 1.949 & 1.699 & 2.496 & 2.669 & 1.814 \\
\hline $\mathrm{Cl}$ & 0.23 & 1.700 & 1.953 & 1.695 & 2.501 & 2.674 & 1.817 \\
\hline $\mathrm{CF}_{3}$ & 0.54 & 1.690 & 1.962 & 1.685 & 2.515 & 2.682 & 1.821 \\
\hline $\mathrm{NO}_{2}$ & 0.78 & 1.679 & 1.971 & 1.674 & 2.525 & 2.696 & 1.830 \\
\hline$R$ & & 0.998 & 0.998 & 0.998 & 0.970 & 0.899 & 0.983 \\
\hline
\end{tabular}

$R$ - correlation coefficient 
Table 3 The $\nabla^{2} \rho, \rho$ and $\mathrm{E}_{\mathrm{HB}}\left[\mathrm{kJ} \mathrm{mol}^{-1}\right]$ of hydrogen bonds in complexes A

\begin{tabular}{llllllll}
\hline & \multicolumn{2}{l}{$\mathrm{OH} \cdots \mathrm{O}$ interaction } & & \multicolumn{2}{l}{$\mathrm{NH} \cdots \mathrm{O}$ interaction } \\
\cline { 2 - 3 } \cline { 7 - 8 } & $\nabla^{2} \rho$ & $\rho$ & $\mathrm{E}_{\mathrm{HB}}$ & & $\nabla^{2} \rho$ & $\rho$ & $\mathrm{E}_{\mathrm{HB}}$ \\
\hline $\mathrm{NMe}_{2}$ & 0.113 & 0.039 & -42.8 & & 0.086 & 0.026 & -25.6 \\
$\mathrm{NH}_{2}$ & 0.114 & 0.040 & -43.7 & & 0.085 & 0.026 & -25.2 \\
$\mathrm{OMe}$ & 0.117 & 0.041 & -45.3 & & 0.083 & 0.025 & -24.4 \\
$\mathrm{Me}$ & 0.118 & 0.041 & -45.9 & & 0.082 & 0.025 & -24.0 \\
$\mathrm{H}$ & 0.119 & 0.042 & -46.7 & & 0.082 & 0.025 & -23.7 \\
$\mathrm{~F}$ & 0.120 & 0.042 & -47.5 & & 0.081 & 0.024 & -23.5 \\
$\mathrm{Cl}$ & 0.121 & 0.043 & -48.0 & 0.081 & 0.024 & -23.2 \\
$\mathrm{CF}$ & 0.123 & 0.044 & -49.4 & & 0.079 & 0.024 & -22.6 \\
$\mathrm{NO}_{2}$ & 0.125 & 0.045 & -51.0 & & 0.078 & 0.023 & -22.1 \\
$R$ & 0.998 & 0.998 & 0.998 & & 0.998 & 0.998 & 0.998 \\
$a$ & 0.0075 & 0.0035 & -5.015 & & -0.0052 & -0.0018 & 2.175 \\
$b$ & 0.1190 & 0.0419 & -46.87 & 0.0817 & 0.0247 & -23.73 \\
\hline
\end{tabular}

agreement with experimental results [18, 21, 22]. For all optimized structures the frequency calculations were ran to check if the geometry is in energy minima (only positive frequencies were obtained). The quantum theory of atoms in molecules (QTAIM) derived data were calculated with the AIM2000 software [43]. The intermolecular interaction energies were calculated with the use of basis set superposition error correction (BSSE) using counterpoise procedure $[44,45]$ with default settings. These were single point calculations at the geometry optimized in the previous step. All energies are zero point energy (ZPE) corrected.

Table 4 The $\nabla^{2} \rho, \rho$ and $\mathrm{E}_{\mathrm{HB}}\left[\mathrm{kJ} \mathrm{mol}^{-1}\right]$ of hydrogen bonds in complexes B

\begin{tabular}{|c|c|c|c|c|c|c|}
\hline & \multicolumn{3}{|c|}{$\mathrm{OH} \cdots \mathrm{O}$ interaction } & \multicolumn{3}{|c|}{$\mathrm{CH} \cdots \mathrm{O}$ interaction } \\
\hline & $\nabla^{2} \rho$ & $\rho$ & $\mathrm{E}_{\mathrm{HB}}$ & $\nabla^{2} \rho$ & $\rho$ & $\mathrm{E}_{\mathrm{HB}}$ \\
\hline $\mathrm{NMe}_{2}$ & 0.116 & 0.040 & -43.9 & 0.0335 & 0.0101 & -8.27 \\
\hline $\mathrm{NH}_{2}$ & 0.117 & 0.040 & -44.8 & 0.0329 & 0.0099 & -8.12 \\
\hline $\mathrm{OMe}$ & 0.119 & 0.042 & -46.3 & 0.0330 & 0.0100 & -8.15 \\
\hline $\mathrm{Me}$ & 0.120 & 0.042 & -46.9 & 0.0316 & 0.0095 & -7.77 \\
\hline $\mathrm{H}$ & 0.122 & 0.043 & -47.7 & 0.0312 & 0.0094 & -7.67 \\
\hline $\mathrm{F}$ & 0.123 & 0.043 & -48.5 & 0.0309 & 0.0093 & -7.60 \\
\hline $\mathrm{Cl}$ & 0.123 & 0.043 & -49.1 & 0.0306 & 0.0092 & -7.52 \\
\hline $\mathrm{CF}_{3}$ & 0.125 & 0.044 & -50.5 & 0.0298 & 0.0090 & -7.31 \\
\hline $\mathrm{NO}_{2}$ & 0.128 & 0.046 & -52.2 & 0.0292 & 0.0088 & -7.16 \\
\hline$R$ & 0.998 & 0.997 & 0.997 & 0.966 & 0.969 & 0.968 \\
\hline$a$ & 0.0072 & 0.0035 & -5.043 & -0.0028 & -0.0009 & 0.715 \\
\hline$b$ & 0.1217 & 0.0427 & -47.95 & 0.0313 & 0.0094 & -7.70 \\
\hline
\end{tabular}

Table 5 The $\nabla^{2} \rho, \rho$ and $\mathrm{E}_{\mathrm{HB}}\left[\mathrm{kJ} \mathrm{mol}^{-1}\right]$ of hydrogen bonds in complexes C

\begin{tabular}{|c|c|c|c|c|c|c|}
\hline & \multicolumn{3}{|c|}{$\mathrm{CH} \cdots \mathrm{O}$ interaction } & \multicolumn{3}{|c|}{$\mathrm{NH} \cdots \mathrm{O}$ interaction } \\
\hline & $\nabla^{2} \rho$ & $\rho$ & $\mathrm{E}_{\mathrm{HB}}$ & $\nabla^{2} \rho$ & $\rho$ & $\mathrm{E}_{\mathrm{HB}}$ \\
\hline $\mathrm{NMe}_{2}$ & 0.0218 & 0.0075 & -5.74 & 0.105 & 0.036 & -37.1 \\
\hline $\mathrm{NH}_{2}$ & 0.0217 & 0.0074 & -5.72 & 0.105 & 0.036 & -36.8 \\
\hline $\mathrm{OMe}$ & 0.0218 & 0.0074 & -5.74 & 0.103 & 0.035 & -35.8 \\
\hline $\mathrm{Me}$ & 0.0216 & 0.0074 & -5.68 & 0.104 & 0.035 & -36.1 \\
\hline $\mathrm{H}$ & 0.0215 & 0.0073 & -5.65 & 0.103 & 0.035 & -35.8 \\
\hline $\mathrm{F}$ & 0.0214 & 0.0073 & -5.63 & 0.102 & 0.035 & -35.4 \\
\hline $\mathrm{Cl}$ & 0.0212 & 0.0072 & -5.57 & 0.102 & 0.035 & -35.1 \\
\hline $\mathrm{CF}_{3}$ & 0.0209 & 0.0071 & -5.48 & 0.101 & 0.034 & -34.6 \\
\hline $\mathrm{NO}_{2}$ & 0.0204 & 0.0069 & -5.30 & 0.100 & 0.033 & -33.8 \\
\hline$R$ & 0.898 & 0.919 & 0.907 & 0.980 & 0.986 & 0.985 \\
\hline$a$ & -0.0008 & -0.0003 & 0.254 & -0.0032 & -0.0016 & 1.949 \\
\hline$b$ & 0.0213 & 0.0073 & -5.60 & 0.1026 & 0.0349 & -35.55 \\
\hline
\end{tabular}

\section{Results and discussion}

The optimized structures of complexes allowed analyzing the geometry, interaction energy and electronic parameters of complexes. Table 1 collects the crucial intermolecular distances for forms A-C and the substituent constants $(\sigma)$ to show the tendency of changes.

The above data shows that the substituent influences intermolecular distances in a classical way-the interatomic distances are in line with the substituent constant, which in turn describes the systematic electronic effect of the substituent on properties of acid/base. The high correlation coefficients $(R$, last row) confirm that the model of linear changes of properties of molecules works also for intermolecular contacts. The smaller value of correlation coefficient for $\mathrm{CH} \cdots \mathrm{O}$ interaction (form $\mathbf{C}$ ) suggest this contact is weak and acts as a support for the stronger $\mathrm{NH} \cdots \mathrm{O}$ one allowing interacting parts of molecules to occupy a common plane. The $\mathrm{CH}^{\cdots} \mathrm{O}$ hydrogen bond length in form $\mathbf{B}$ correlates better with substituent constant than that in $\mathbf{C}$. This may be caused by the increased strength of $\mathrm{OH} \cdots \mathrm{O}$ hydrogen bond with respect to the $\mathrm{NH} \cdots \mathrm{O}$ one (the $\mathrm{OH} \cdots \mathrm{O}$ is, in general [47], stronger than $\mathrm{NH}^{\cdots} \mathrm{O}$ hydrogen bond - form $\mathbf{B}$ vs. C). Also the $\mathrm{CH} \cdots \mathrm{O}$ hydrogen bond distances suggest this interaction in $\mathbf{B}$ is stronger than in $\mathbf{C}$. The intermolecular interaction energies $\left(\mathrm{E}_{\text {int }}\right)$ corrected to $\mathrm{ZPE}$ and BSSE [44] are collected in Table 2. The same table contains
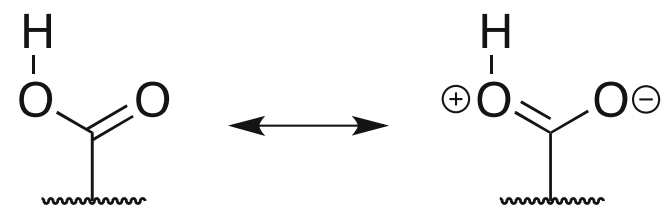

Fig. 2 Mesomeric forms of -COOH group 
Fig. 3 The attractive and repulsive secondary interactions in studied complexes

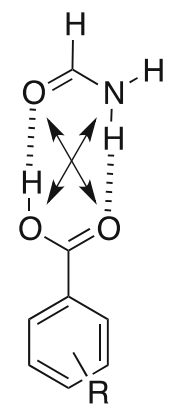

(1)

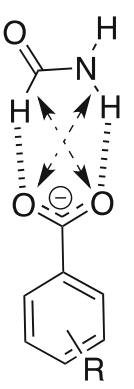

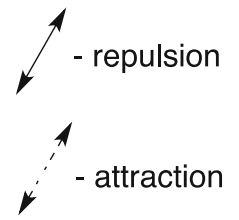

the correlation coefficient $(R)$ for $\mathrm{E}_{\text {int }}=a(\sigma)+b$ function and $a$, $b$, and $\sigma$ (substituent constant) values.

It is interesting that the response of the $E_{\text {int }}$ to the substituent is stronger in $\mathbf{B}$ form with respect to the $\mathbf{A}$ form by the factor of $1.74(-3.69 /-2.12=1.74)$. This is expressed by steeper linear function for $\mathbf{B}$ than that for A (compare the ' $a$ ' values in Table 2). It is worth pointing out that ' $a$ ' (Table 2) have opposite sign for acid series than that for anion series. This is in agreement with the acid/base properties of these species, i.e., the electron-accepting substituent increase the acidity of an acid and lowers the basicity of the conjugated base. In order to get a deeper insight into the properties of the studied complexes the QTAIM [48] analysis was performed. Tables 3, 4 and 5 collect the data of Laplacian of the electron density $\left(\nabla^{2} \rho\right)$, electron density $(\rho)$ at the hydrogen bond critical point (H-BCP) and the energy of the hydrogen bond $\left(\mathrm{E}_{\mathrm{HB}}\right)$ calculated by the Espinosa approach $[49,50]$. The $\nabla^{2} \rho$ and $\rho$ values are limited to three decimals for stronger interactions and four for weaker ones. Similarly, the values of $\mathrm{E}_{\mathrm{HB}}$ are limited to one decimal for stronger interactions and two for weaker ones. This is to show numerically the tendency of changes upon change of the substituent. The last three rows collect correlation coefficients $(R)$ for the following linear function property $\left(\nabla^{2} \rho, \rho\right.$ or $\left.\mathrm{E}_{\mathrm{HB}}\right)=a$ $(\sigma)+b$ and $a$ (slope) and $b$ (intercept) values.

First of all it is necessary to mention that in all complexes formed the values of the Laplacian of the electron density at H-BCP show the interaction is of hydrogen bond nature [51]. The QTAIM) theory says the Laplacian is negative for covalent bonds and positive for hydrogen bonds. It is commonly known that the
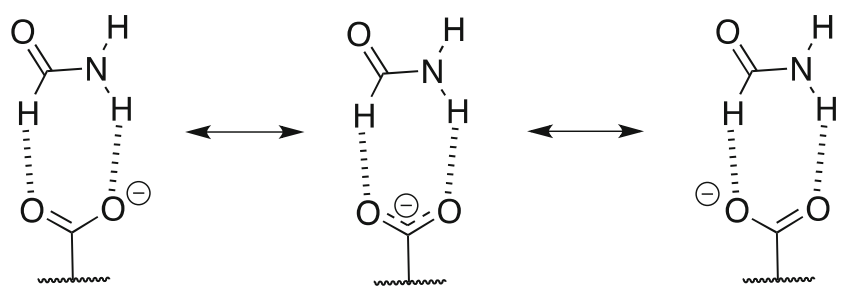

Fig. 4 The mesomerism in carboxylate in hydrogen-bonded complex
- $\mathrm{COOH}$ moiety acts as a hydrogen bond donor $(\mathrm{OH}$ group) and acceptor $(\mathrm{C}=\mathrm{O}$ group) at the same time. As the substituent became more electron-accepting it makes the hydrogen bond donation ability of $\mathrm{OH}$ higher and hydrogen bond accepting ability of $\mathrm{C}=\mathrm{O}$ lower. The opposite signs of the ' $a$ ' values in $\mathrm{E}_{\mathrm{HB}}$ columns show that (Tables 3 and 4), while the said slopes are positive for complexes $\mathbf{C}$ (Table 5). Due to the different electronegativity of nitrogen and carbon atoms the difference between $\mathrm{NH} \cdots \mathrm{O}$ and $\mathrm{CH} \cdots \mathrm{O}$ is obvious making the latter interaction weaker. The $\mathrm{OH} \cdots \mathrm{O}$ interaction is about $1.0 \mathrm{~kJ} \mathrm{~mol}^{-1}$ stronger in $\mathbf{B}$ form than that in $\mathbf{A}$ form. This suggests that the weak $\mathrm{CH} \cdots \mathrm{O}$ interaction supports five to seven times stronger $\mathrm{OH} \cdots \mathrm{O}$ one, while the $\mathrm{NH} \cdots \mathrm{O}$ in $\mathbf{A}$ complexes participates much more in overall stabilization. The relative $\mathrm{E}_{\mathrm{HB}}$ energy in complexes A $\left(\mathrm{E}_{\mathrm{HB}}{ }^{(\mathrm{OH} \cdots \mathrm{O})} / \mathrm{E}_{\mathrm{HB}}{ }^{\left(\mathrm{NH}^{\cdots} \mathrm{O}\right)}\right)$ and $\mathbf{B}\left(\mathrm{E}_{\mathrm{HB}}(\mathrm{OH} \cdots \mathrm{O}) /\right.$ $\mathrm{E}_{\mathrm{HB}}(\mathrm{CH} \cdots \mathrm{O})$ is the lowest for $\mathrm{NMe}_{2}$ and the highest for $\mathrm{NO}_{2}$ groups, respectively. Moreover, the said ratios defined as $\mathrm{x}_{1}=\mathrm{E}_{\mathrm{HB}}(\mathrm{OH} \cdots \mathrm{O}) / \mathrm{E}_{\mathrm{HB}}(\mathrm{NH} \cdots \mathrm{O})$ in series $\mathbf{A}$ and $x_{2}=\mathrm{E}_{\mathrm{HB}}(\mathrm{OH} \cdots \mathrm{O}) / \mathrm{E}_{\mathrm{HB}}(\mathrm{CH} \cdots \mathrm{O})$ in series $\mathbf{B}$ are dependent from the substituent constants as: $\mathrm{x}_{1}=0.39 \sigma+1.98$ $(R=0.997)$ and $x_{2}=1.23 \sigma+6.25 \quad(R=0.989)$. The higher slope in the second equation confirms that $\mathrm{CH} \cdots \mathrm{O}$ interaction is weak while the slope in the first equation suggests the $\mathrm{NH} \cdots \mathrm{O}$ is much stronger than the $\mathrm{CH} \cdots \mathrm{O}$ one in series $\mathbf{B}$ (for equal contribution of interactions
Table 6 Energies [kJ $\left.\mathrm{mol}^{-1}\right]\left(\Delta \mathrm{E}_{1-3}\right)$ for reactions $1-3$ 
Fig. 5 The association of formamide by the acid and benzoate ( $\mathrm{D}$ associates)

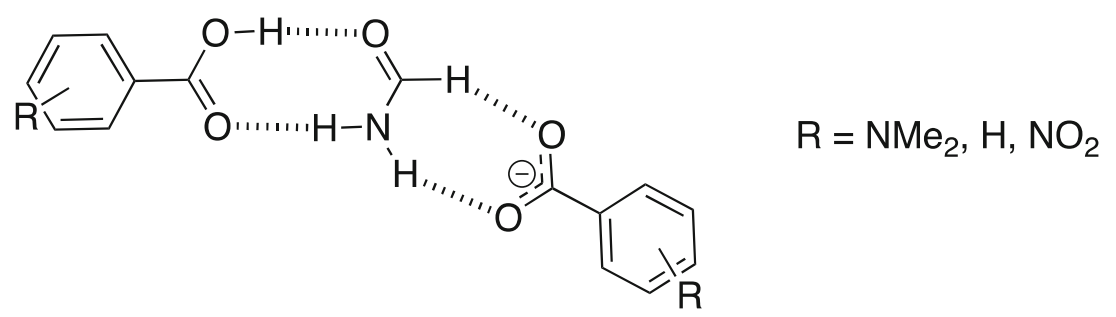

the slope should be equal to zero and the intercept equal to one). The $\mathrm{E}_{\mathrm{HB}}$ of $\mathrm{OH} \cdots \mathrm{O}$ in $\mathbf{A}$ and $\mathbf{B}$ series are very similar. The above observations can also be seen in the geometry of the complexes (Table 1). The electron densities at H-BCPs in studied series are in line with the general trends in hydrogen bonding abilities of respective groups. The QTAIM data and above analysis gives the basis to the conclusion that two mesomeric forms of the - $\mathrm{COOH}$ moiety (Fig. 2) have their contributions dependent on the substituent and the hydrogenbonding counterpart. The electron density on both oxygen atoms is, of course, dependent on substituent (SI, Chart S1). Increased $\mathrm{E}_{\mathrm{HB}}$ for $\mathrm{OH} \cdots \mathrm{X}$ and decreased for $\mathrm{H} \cdots \mathrm{O}=\mathrm{C}$ hydrogen bonds suggests the charge is transmitted within the $-\mathrm{COOH}$ group.

It is also worth mentioning that in associates the charge at the formamide proton forming hydrogen bond slightly increases (SI, Chart S2) with the increasing electron accepting properties of the substituent. This may be explained by the intra- $\mathrm{COOH}$ group conjugation.

In the third series (complexes $\mathbf{C}$ ) the $\mathrm{E}_{\text {int }}$ data shows that more electron-withdrawing substituent lowers the basicity of the carboxylate and thus weakens association. As in previous series the $\nabla^{2} \rho$ is positive exhibiting the hydrogen bonding nature of interaction. Similarly as in series $\mathbf{B}$ its value and the value of $\rho$ are almost an order of magnitude lower for weak

Table 7 The hydrogen bond energy $\left(\mathrm{E}_{\mathrm{HB}}\left[\mathrm{kJ} \mathrm{mol}^{-1}\right]\right)$ in complexes of formamide with acids and benzoates D

\begin{tabular}{|c|c|c|c|c|c|}
\hline \multicolumn{3}{|c|}{ Acid side } & \multicolumn{3}{|c|}{ Anion side } \\
\hline \multicolumn{3}{|c|}{$\mathrm{E}_{\mathrm{HB}}\left[\mathrm{kJ} \mathrm{mol}^{-1}\right]$} & \multicolumn{3}{|c|}{$\mathrm{E}_{\mathrm{HB}}\left[\mathrm{kJ} \mathrm{mol}^{-1}\right]$} \\
\hline $\mathrm{R}$ & $\mathrm{OH} \cdots \mathrm{O}$ & $\mathrm{NH} \cdots \mathrm{O}$ & $\mathrm{NH} \cdots \mathrm{O}$ & $\mathrm{CH} \cdots \mathrm{O}$ & $\mathrm{R}$ \\
\hline $\mathrm{NO}_{2}$ & -63.6 & -17.8 & -36.2 & -6.8 & $\mathrm{NO}_{2}$ \\
\hline $\mathrm{NO}_{2}$ & -65.2 & -17.1 & -38.5 & -7.3 & $\mathrm{H}$ \\
\hline $\mathrm{NO}_{2}$ & -66.0 & -17.2 & -39.8 & -7.6 & $\mathrm{NMe}_{2}$ \\
\hline $\mathrm{H}$ & -57.9 & -17.8 & -35.0 & -6.7 & $\mathrm{NO}_{2}$ \\
\hline $\mathrm{H}$ & -59.7 & -17.0 & -36.2 & -7.9 & $\mathrm{H}$ \\
\hline $\mathrm{H}$ & -59.6 & -17.1 & -38.9 & -7.2 & $\mathrm{NMe}_{2}$ \\
\hline $\mathrm{NMe}_{2}$ & -51.6 & -19.4 & -34.2 & -5.1 & $\mathrm{NO}_{2}$ \\
\hline $\mathrm{NMe}_{2}$ & -53.6 & -18.7 & -35.8 & -7.1 & $\mathrm{H}$ \\
\hline $\mathrm{NMe}_{2}$ & -54.7 & -17.5 & -35.8 & -8.0 & $\mathrm{NMe}_{2}$ \\
\hline
\end{tabular}

interaction with $\mathrm{CH}$ proton than that with much stronger interacting $\mathrm{OH}$ and $\mathrm{NH}$ ones. Also, as in $\mathbf{B}$ series, the values of $R$ are lower for interaction with $\mathrm{CH}$ than that with $\mathrm{NH}$. The slopes for all QTAIM-derived data in series $\mathbf{C}$ fitted to the linear function of the substituent constant are negative, which is in agreement with the general influence of the substituent on basicity. The change in $\mathrm{E}_{\mathrm{HB}}$ of $\mathrm{NH} \cdots \mathrm{O}$ in series $\mathbf{A}$ and $\mathbf{C}$ is similar (compare the slopes in Tables 3 and 5). This means that these groups behave similarly independently if the interacting ' $\mathrm{X}$ ' atom in $\mathrm{NH} \cdots \mathrm{X}$ hydrogen bond is neutral or has an anionic character as in series $\mathbf{C}$ however an increase of interaction is noticed for anions. The geometric and energetic parameters in series $\mathbf{C}$ correlate with substituent constants. Also, as before, the correlation is higher for a strong interaction $(\mathrm{NH} \cdots \mathrm{O})$ than for a weak one $\left(\mathrm{CH}^{\cdots} \mathrm{O}\right)$. It was recently shown [18] that the interaction with substituted benzoates is driven by the character of the substituent when associated with urea by two, close in energy $\mathrm{NH} \cdots \mathrm{O}$ hydrogen bonds. Here the $\mathrm{NH} \cdots \mathrm{O}$ hydrogen bond is much stronger (more than six times) than the $\mathrm{CH} \cdots \mathrm{O}$ interaction. The last interaction still follows the trend of the value of substituent constant. It is worth noting that the $E_{\text {int }}$ for complexes in $\mathbf{C}$ series is higher than any $E_{\text {int }}$ in $\mathbf{B}$, while the former have comparable $E_{\text {int }}$ to series $\mathbf{A}$ but with reversed order of changes in the light of substituent effect. On the other hand the sum of energies of hydrogen bonds in $\mathbf{C}$ is smaller than that in $\mathbf{B}$ (compare also the $\mathrm{E}_{\text {int }}$ values). This is caused by described earlier differences in topology of the complexes and hydrogen bonding patterns. In series $\mathbf{C}$ all intermolecular interactions are attractive while in $\mathbf{A}$ and B there are also repulsions (Fig. 3 shows secondary interactions). The concept of the secondary interactions [52] as forces that fulfill the palate of intermolecular interactions has been generally accepted by chemists. It says that in hydrogen-bonded complexes weak secondary interactions act diagonally within a cyclic system stabilized by hydrogen bonds. Thus, like groups repel while opposite in character attract each other. Solid and dashed arrows as in Fig. 3 usually depict these interactions.

The data for the C-O bond lengths in benzoate suggest these are not equivalent as they are in the case of isolated molecules. The $\mathrm{NH} \cdots \mathrm{O}$ hydrogen bonded oxygen atom forms 
Fig. 6 The changes in $\mathrm{E}_{\mathrm{HB}}$ upon complexation of formamide with another counterpart

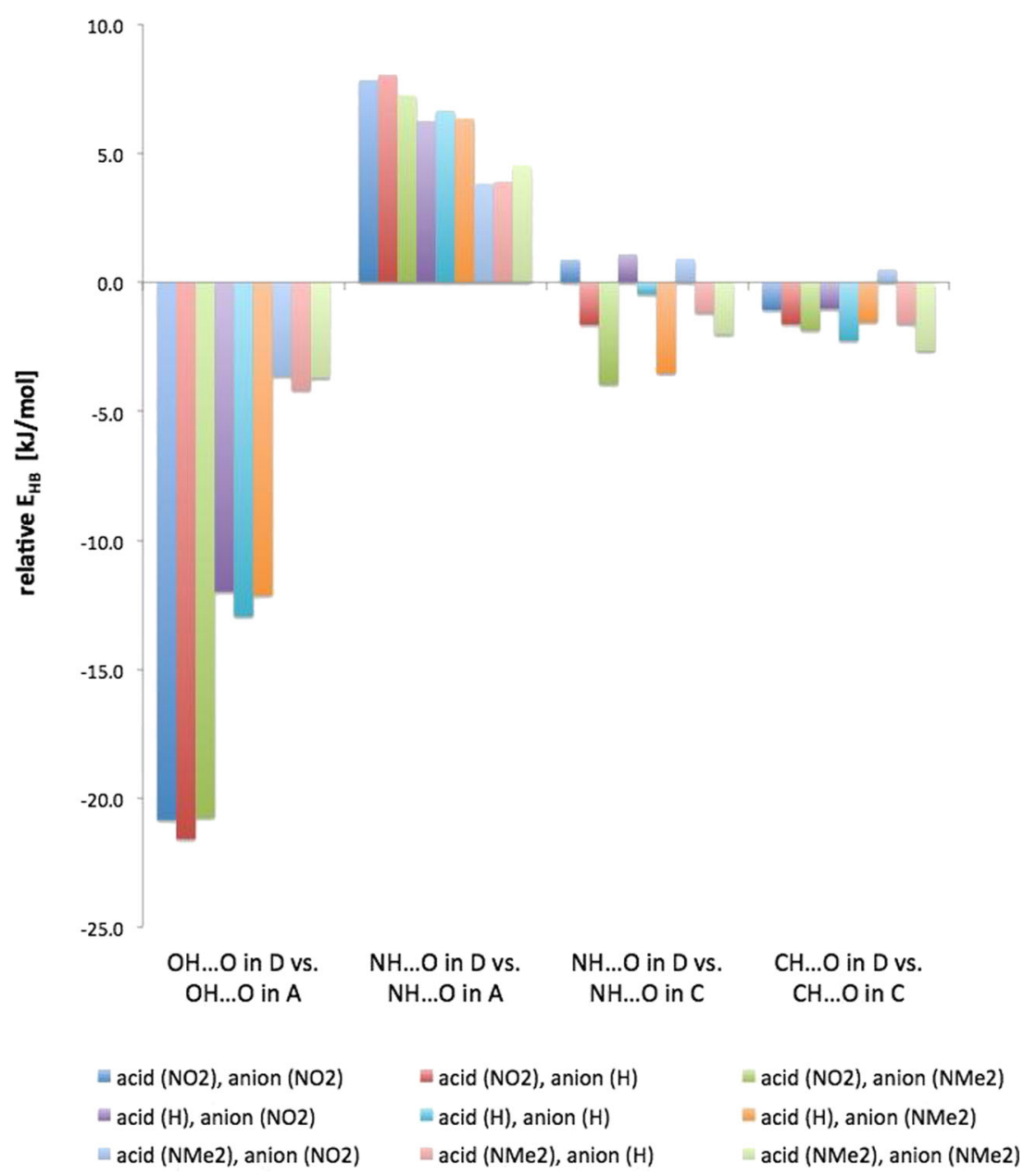

a $0.012 \AA$ longer bond to carbon atom than that of the oxygen entangled by $\mathrm{CH} \cdots \mathrm{O}$ interaction. Although the difference is very small it is reasonable to conclude that the $\mathrm{CH} \cdots \mathrm{O}$ interacting oxygen forms a little bit more double in character

Table 8 The hydrogen bond distances in $\mathbf{D}$ associates

\begin{tabular}{|c|c|c|c|c|c|}
\hline \multicolumn{3}{|c|}{ Acid side } & \multicolumn{3}{|c|}{ Anion side } \\
\hline \multicolumn{3}{|c|}{ Hydrogen bond length $[\AA]$} & \multicolumn{3}{|c|}{ Hydrogen bond length $[\AA]]$} \\
\hline $\mathrm{R}$ & $\mathrm{OH} \cdots \mathrm{O}$ & $\mathrm{NH} \cdots \mathrm{O}$ & $\mathrm{NH} \cdots \mathrm{O}$ & $\mathrm{CH} \cdots \mathrm{O}$ & $\mathrm{R}$ \\
\hline $\mathrm{NO}_{2}$ & 1.611 & 2.058 & 1.806 & 2.566 & $\mathrm{NO}_{2}$ \\
\hline $\mathrm{NO}_{2}$ & 1.604 & 2.073 & 1.786 & 2.531 & $\mathrm{H}$ \\
\hline $\mathrm{NO}_{2}$ & 1.600 & 2.072 & 1.775 & 2.517 & $\mathrm{NMe}_{2}$ \\
\hline $\mathrm{H}$ & 1.642 & 2.058 & 1.817 & 2.573 & $\mathrm{NO}_{2}$ \\
\hline $\mathrm{H}$ & 1.633 & 2.075 & 1.807 & 2.495 & $\mathrm{H}$ \\
\hline $\mathrm{H}$ & 1.633 & 2.073 & 1.782 & 2.543 & $\mathrm{NMe}_{2}$ \\
\hline $\mathrm{NMe}_{2}$ & 1.678 & 2.023 & 1.822 & 2.697 & $\mathrm{NO}_{2}$ \\
\hline $\mathrm{NMe}_{2}$ & 1.668 & 2.039 & 1.811 & 2.551 & $\mathrm{H}$ \\
\hline $\mathrm{NMe}_{2}$ & 1.660 & 2.062 & 1.807 & 2.481 & $\mathrm{NMe}_{2}$ \\
\hline
\end{tabular}

bond to carboxylic carbon atom than $\mathrm{NH} \cdots \mathrm{O}$ hydrogen bonded oxygen. This may also be interpreted as the subtle balance between the mesomeric forms present in the complex of carboxylate (Fig. 4). The mentioned data show that the structure on the left hand-side is a little bit more important that the one on the right hand-side.

To further study the driving forces in complexation of formamide the reactions expressed by equations 1-3 were used. Table 6 collects the energetic data.

Form $\mathrm{A}+$ anion $\rightarrow$ Form $\mathrm{C}+$ acid $+\Delta \mathrm{E}_{1}$

Form $\mathrm{B}+$ anion $\rightarrow$ Form $\mathrm{C}+$ acid $+\Delta \mathrm{E}_{2}$

Form $\mathrm{A}+$ anion $\rightarrow$ Form $\mathrm{C}+$ acid $+\Delta \mathrm{E}_{3}$

The negative values in Table 6 show that reactions are exothermic $\left(\Delta E_{2}\right)$, mixed depending on substituent $\left(\Delta E_{1}\right)$, while the $\Delta E_{3}$ values suggest change from form $\mathbf{A}$ to $\mathbf{B}$ is not preferred. It is worth pointing out that the $\mathrm{E}_{\text {int }}(\mathbf{B})$ and $\mathrm{E}_{\text {int }}(\mathbf{C})$ (Table 2) change in opposite ways referring to the 


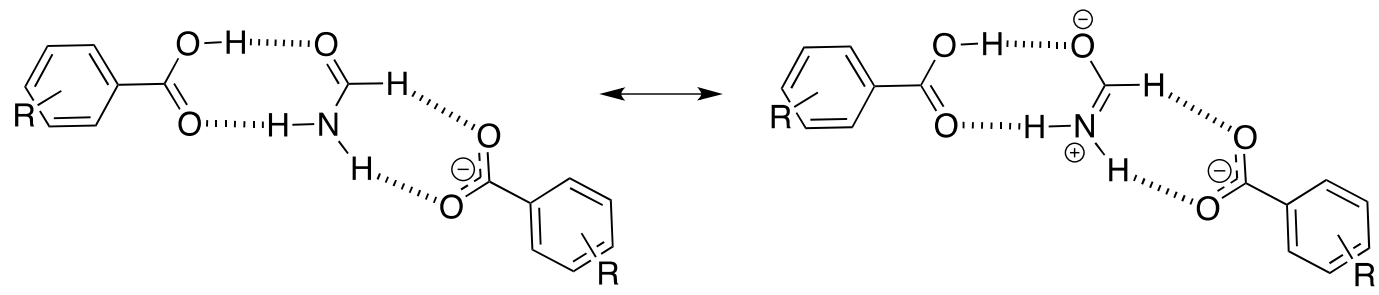

a

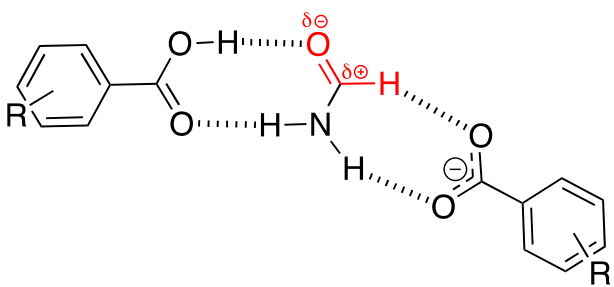

b

Fig. 7 Two possible polarizations of the formamide molecule in D associates

substituent constant order. Also these is no surprise that form $\mathbf{B}$ converts into $\mathbf{C}$ readily exchanging two repulsive interactions by two attractive (Fig. 3) although one hydrogen bond $(\mathrm{CH} \cdots \mathrm{O}$ in $\mathbf{C})$ is weak.

Since the acid/benzoate equilibrium may be tuned by $\mathrm{pH}$ the simultaneous association by the acid and benzoate at a time may be considered. Thus, to have a better understanding of the substituent effect on association of acid and benzoate with formamide a series of calculations were employed. Figure 5 shows the associates that were investigated. Due to time consuming calculations only three substituents were used, i.e., extreme donor and acceptor and a neutral one.

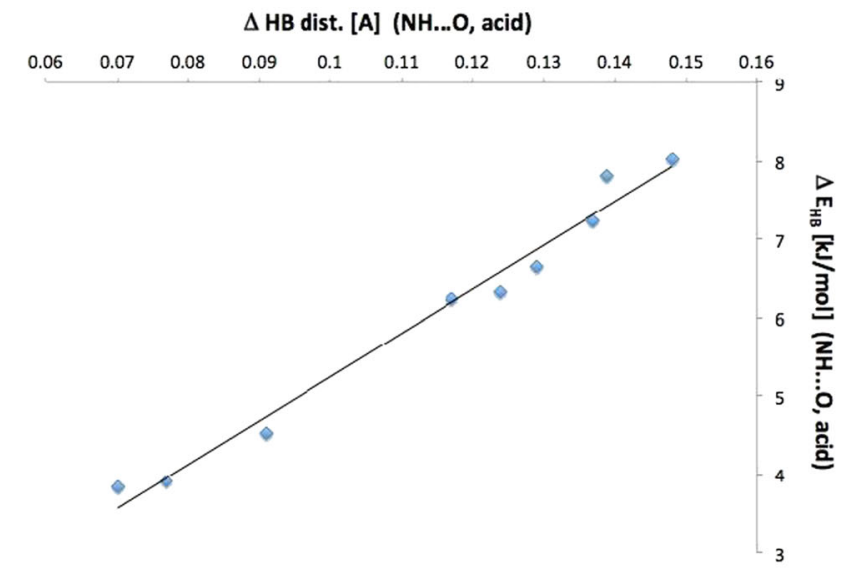

b

$\Delta \mathrm{HB}$ dist. [A] (CH...O, anion)

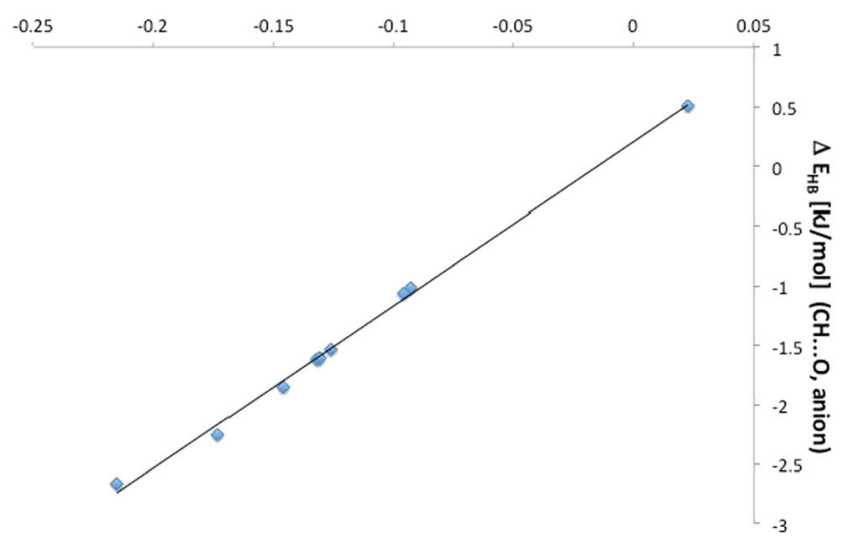

d

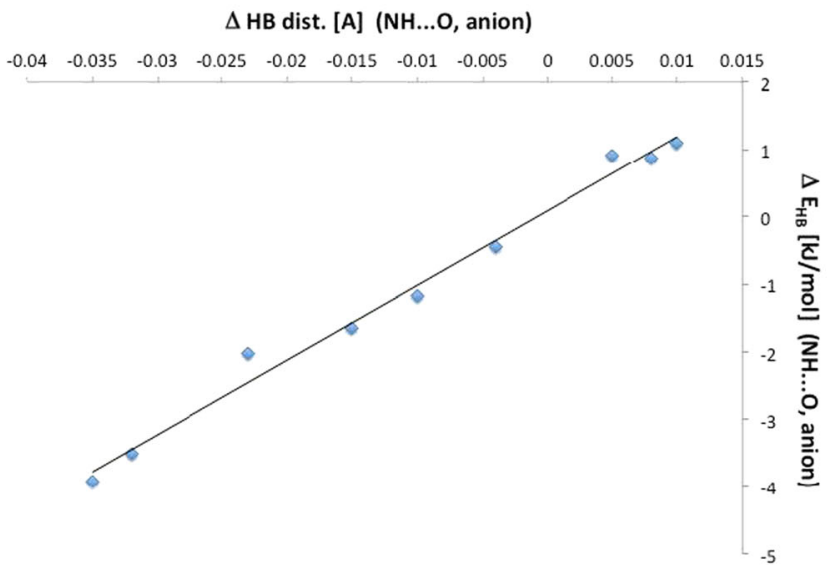

C

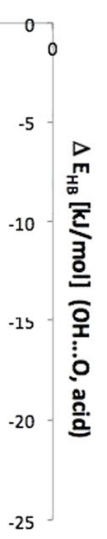

Fig. 8 The correlation charts for changes in hydrogen bond distance $(\Delta \mathrm{HB}$ dist. $[\AA])$ and changes in energy of hydrogen bond $\left(\Delta \mathrm{E}_{\mathrm{HB}}\left[\mathrm{kJ} \mathrm{mol}^{-1}\right]\right)$ 
Table 7 collects the $\mathrm{E}_{\mathrm{HB}}$ for the complexes shown in Fig. 5 . The values of $\nabla^{2} \rho$ and $\rho$ are collected in supplementary material.

The data in Table 7 show some interesting features. The cooperativity effect [53] is noticed, i.e.: $a$ ) the $\mathrm{OH} \cdots$ $\mathrm{O}$ interaction of acid became much stronger in $\mathbf{D}$ complexes than in complex $\mathbf{A}, b$ ) consequently the $\mathrm{NH}^{\cdots} \mathrm{O}$ interaction in $\mathbf{D}$ involving acid became weaker than in form $\mathbf{A}, c$ ) except for $\mathrm{NO}_{2}$ substituted anion the $\mathrm{NH} \cdots \mathrm{O}$ with benzoate is stronger in $\mathbf{D}$ complexes than in form $\mathbf{C}$, $d$ ) for the hydrogen bonding with acids and keeping the acid the same the extreme change of $\mathrm{E}_{\mathrm{HB}}$ is observed for unsubstituted anion $\left(\mathrm{E}_{\mathrm{HB}}{ }^{\text {(acid) }}\right.$ in $\mathbf{D}$ vs. $\mathrm{E}_{\mathrm{HB}}{ }^{\text {(acid) }}$ in $\left.\mathbf{A}\right)$. These observations are depicted in Fig. 6. Negative values in Fig. 6 mean stronger interaction in $\mathbf{D}$ complex than in $\mathbf{A}$ or $\mathbf{C}$ forms. Here only the series $\mathbf{A}$ and $\mathbf{C}$ were compared to $\mathbf{D}$ because the topology of the $\mathbf{D}$ series is a superposition of topologies of $\mathbf{A}$ and $\mathbf{C}$ ones.

The said increase in energy of interaction has consequences on intermolecular distances. Table 8 collects the hydrogenbond lengths in $\mathbf{D}$ associates.

Interestingly the energetic and geometrical data in $\mathbf{D}$ complexes suggest the polarization of the $\mathrm{CH}$ (Fig. $7 b$ ) bond rather than charge transfer from nitrogen to oxygen atom (mesomerism, Fig. 7a). This explains why the weak $\mathrm{CH} \cdots \mathrm{O}$ interaction with anions in $\mathbf{D}$ is stronger than that in $\mathbf{C}$ series.

The variability of the hydrogen bond lengths and $\mathrm{E}_{\mathrm{HB}}$ calculated by Espinosa approach are linearly dependent. In Fig. 8 the correlation charts for these dependencies are shown.

For these linear functions the correlation coefficients are: $R=0.998(a), 0.990(b), 0.994(c)$, and $0.998(d)$. This shows that the Espinosa's approach $[49,50]$ is applicable also in cases of other than originally developed for interactions $(\mathrm{OH} \cdots \mathrm{O}, \mathrm{NH} \cdots \mathrm{O}, \mathrm{CH} \cdots \mathrm{F}, \mathrm{FH} \cdots \mathrm{F}, \mathrm{FH} \cdots \mathrm{N})$ [54-57]. This has also been shown for other interactions including intramolecular hydrogen bonding [58] and the negatively charged species as oxyanions [18] or $\pi-\mathrm{H} \cdots \mathrm{O}$ contacts [59].

Table 9 The ZPE and BSSE corrected interaction energy $\left(E_{\text {int }}\right)$ for $\mathbf{D}$ complexes and values of $\Delta \mathrm{E}_{4}$

\begin{tabular}{llll}
\hline $\mathrm{R}$ acid side & $\mathrm{R}$ anion side & $\mathrm{E}_{\text {int }}\left[\mathrm{kJ} \mathrm{mol}^{-1}\right]$ & $\Delta \mathrm{E}_{4}\left[\mathrm{~kJ} \mathrm{~mol}^{-1}\right]$ \\
\hline $\mathrm{NO}_{2}$ & $\mathrm{NO}_{2}$ & -83.1 & -77.0 \\
$\mathrm{NO}_{2}$ & $\mathrm{H}$ & -87.3 & -81.2 \\
$\mathrm{NO}_{2}$ & $\mathrm{NMe}_{2}$ & -89.5 & -83.3 \\
$\mathrm{H}$ & $\mathrm{NO}_{2}$ & -77.9 & -73.9 \\
$\mathrm{H}$ & $\mathrm{H}$ & -81.1 & -77.0 \\
$\mathrm{H}$ & $\mathrm{NMe}_{2}$ & -82.4 & -78.2 \\
$\mathrm{NMe}_{2}$ & $\mathrm{NO}_{2}$ & -72.9 & -70.3 \\
$\mathrm{NMe}_{2}$ & $\mathrm{H}$ & -75.7 & -73.1 \\
$\mathrm{NMe}_{2}$ & $\mathrm{NMe}_{2}$ & -76.5 & -73.7 \\
\hline
\end{tabular}

Table 9 collects the ZPE and BSSE corrected $\mathrm{E}_{\text {int }}$ values for D complexes and the results of the reaction expressed by Eq. 4.

Form $\mathrm{A}+$ anion $\rightarrow$ Form $\mathrm{C}+$ acid $+\Delta \mathrm{E}_{4}$

The $\mathrm{E}_{\text {int }}$ for $\mathbf{D}$ complexes shows that: $a$ ) the higher acidity of the acid determine the overall interaction in threesome complexes carrying the same acid but different anion (compare the $\mathrm{E}_{\text {int }}$ for the series with $\mathrm{NO}_{2}$-substituted acid and $\mathrm{E}_{\text {int }}$ with remaining acids) and $b$ ) the order of energy of interaction within the series carrying the same acid is determined by the character of the anion. It is worth keeping in mind that the $\mathrm{E}_{\text {int }}$ and $\Delta \mathrm{E}_{4}$ in Table 9 are close to each other although those describe various properties. The $\mathrm{E}_{\mathrm{int}}$ describes the intermolecular interactions in complexes $\mathbf{D}$ while $\Delta \mathrm{E}_{4}$ include the electron reorganization and geometry relaxation upon association of an anion with complexes $\mathbf{A}$. The charge at the formamide atoms is higher at nitrogen, oxygen, and carbon atoms than that in referring A-C complexes. The higher electron density is also observed on $\mathrm{NH}$ proton (acid side) of the formamide in any complex in $\mathbf{D}$ series than that in $\mathbf{A}$. The charge is lowered at protons on the anion side ( $\mathrm{CH}$ and $\mathrm{NH}$ ) of the complexes $\mathbf{D}$ with respect to the values for associates $\mathbf{C}(\mathrm{SI})$. This suggests the charge transfer character of the interactions. These observations, however, are not the main topic of the current publication and will be used in more detailed analysis based on a larger population of complexes.

\section{Conclusions}

The case study of formamide complexation with substituted benzoic acids and respective benzoates showed that formamide might be a molecule of choice for studying basic intermolecular interactions also in triple associates in various arrangements. The systematic changes of the substituent from electrondonating to electron-accepting revealed that in the case of acids the effect is transmitted to $\mathrm{OH}$ and $\mathrm{C}=\mathrm{O}$ groups making them a better hydrogen bond donor and a worse hydrogen bond acceptor at a time. Opposite to that the symmetric $-\mathrm{CO}_{2}^{-}$moiety being a weaker base as the substituent changes to electronaccepting is a weaker hydrogen bond acceptor. In the case when both, acid and benzoate, interacts with the formamide molecule the cooperativity is observed. High correlation coefficients for properties used to describe the intermolecular interactions prove that substituent effect should be taken into account in supramolecular complexes also when weak interactions with $\mathrm{CH}$ group is considered. The agreement between general substituent effect and the QTAIM-derived data show this theory successfully describes intermolecular interactions of hydrogen bonded complexes of formamide and substituted benzoic acids and benzoates in this study. 


\section{Supplement}

Supporting information file contains the Cartesians for the optimized structures, their energies and values of the Laplacian and electron density at H-BCP in $\mathbf{D}$ complexes and the natural charges charts.

Acknowledgments The author is much indebted to the ICM in Warsaw for providing computer time and programs.

Open Access This article is distributed under the terms of the Creative Commons Attribution License which permits any use, distribution, and reproduction in any medium, provided the original author(s) and the source are credited.

\section{References}

1. Prins LJ, Reinhoudt DN, Timmerman P (2001) Noncovalent synthesis using hydrogen bonding. Angew Chem Int Ed 40(13):2382-2426. doi:10.1002/1521-3773(20010702)40:13<2382:aid-anie2382>3.0. co;2-g

2. Desiraju GR (1995) Supramolecular synthons in crystal engineering - a new organic synthesis. Angew Chem Int Ed 34(21):23112327. doi:10.1002/anie.199523111

3. Sarma JARP, Desiraju GR (1986) The role of Cl...Cl and C-H.O interactions in the crystal engineering of 4-. ANG. short-axis structures. Acc Chem Res 19(7):222-228. doi:10.1021/ar00127a005

4. Desiraju GR (2010) Crystal engineering: A brief overviwe. J Chem Sci 122:667-675

5. Berda EB, Foster EJ, Meijer EW (2010) Toward controlling folding in synthetic polymers: fabricating and characterizing supramolecular single-chain nanoparticles. Macromolecules 43(3):1430-1437. doi: 10.1021/ma902393h

6. Brunsveld L, Folmer BJB, Meijer EW, Sijbesma RP (2001) Supramolecular polymers. Chem Rev 101(12):4071-4098. doi:10. 1021/cr990125q

7. De Greef TFA, Smulders MMJ, Wolffs M, Schenning APHJ, Sijbesma RP, Meijer EW (2009) Supramolecular polymerization. Chem Rev 109(11):5687-5754. doi:10.1021/cr900181u

8. Nie L, Li Z, Han J, Zhang X, Yang R, Liu W-X, Wu F-Y, Xie J-W, Zhao Y-F, Jiang Y-B (2004) Development of N-Benzamidothioureas as a NEW generation of thiourea-based receptors for anion recognition and sensing. J Org Chem 69(19):6449-6454. doi:10.1021/ jo049088f

9. Rostami A, Colin A, Li XY, Chudzinski MG, Lough AJ, Taylor MS (2010) N, N'-diarylsquaramides: general, high-yielding synthesis and applications in colorimetric anion sensing. J Org Chem 75(12): 3983-3992. doi:10.1021/jo100104g

10. Sun XH, Li W, Xia PF, Luo H-B, Wei Y, Wong MS, Cheng Y-K, Shuang S (2007) Phenyl-calix[4]arene-based fluorescent sensors: cooperative binding for carboxylates. J Org Chem 72(7):24192426. doi:10.1021/jo062258z

11. Zhao Y-P, Wu L-Z, Si G, Liu Y, Xue H, Zhang L-P, Tung C-H (2007) Synthesis, spectroscopic, electrochemical and $\mathrm{Pb} 2+-$ binding studies of tetrathiafulvalene acetylene derivatives. J Org Chem 72(10):3632 3639. doi:10.1021/jo0622577

12. Chou H-C, Hsu C-H, Cheng Y-M, Cheng C-C, Liu H-W, Pu S-C, Chou P-T (2004) Multiple hydrogen bonds tuning guest/host excited- state proton transfer reaction: its application in molecular recognition. J Am Chem Soc 126(6):1650-1651. doi:10.1021/ja039240f

13. Zhang S, Echegoyen L (2005) Selective anion sensing by a tris-amide CTV derivative: $1 \mathrm{H}$ NMR titration, self-assembled monolayers, and impedance spectroscopy. J Am Chem Soc 127(6):2006-2011. doi: $10.1021 / \mathrm{ja} 044411 \mathrm{~h}$

14. Moerkerke S, Le Gac S, Topić F, Rissanen K, Jabin I (2013) Selective extraction and efficient binding in a protic solvent of contact Ion triplets by using a thiourea-based Bis-calix[6]arene receptor. Eur J Org Chem 2013(24):5315-5322. doi:10.1002/ejoc.201300639

15. Hammett LP (1937) The effect of structure upon the reactions of organic compounds. Benzene derivatives. J Am Chem Soc 59(1):96103. doi:10.1021/ja01280a022

16. Cooke G, Rotello VM (2002) Methods of modulating hydrogen bonded interactions in synthetic host-guest systems. Chem Soc Rev 31(5):275-286. doi:10.1039/b103906g

17. Wang H-B, Mudraboyina BP, Wisner JA (2012) Substituent effects in double-helical hydrogen-bonded AAA-DDD complexes. Chem Eur J 18(5):1322-1327. doi:10.1002/chem.201103001

18. Ośmiałowski B, Mroczyńska K, Kolehmainen E, Kowalska M, Valkonen A, Pietrzak M, Rissanen K (2013) Association of N(pyridin-2-yl), N'-substituted ureas with 2-amino-1,8-naphthyridines and benzoates: NMR and quantum chemical studies of the substituent effect on complexation. J Org Chem 78(15):7582-7593. doi:10. 1021/j04011393

19. Costero AM, Peransi S, Gil S (2006) A selective colorimetric chemodosimeter for the naked eye detection of benzoate anion. Tetrahedron Lett 47(37):6561-6564. doi:10.1016/j.tetlet.2006.07.019

20. Hunter CA, Low CMR, Rotger C, Vinter JG, Zonta C (2002) Substituent effects on cation $-\pi$ interactions: a quantitative study. PNAS 99(8):4873-4876. doi:10.1073/pnas.072647899

21. Ośmiałowski B, Kolehmainen E, Ikonen S, Valkonen A, Kwiatkowski A, Grela I, Haapaniemi E (2012) 2-acylamino- and 2,4-Bis(acylamino)pyrimidines as supramolecular synthons analyzed by multiple noncovalent interactions. DFT, X-ray diffraction, and NMR spectral studies. J Org Chem 77(21):9609-9619. doi:10. 1021/jo301643z

22. Ośmiałowski B, Kolehmainen E, Kowalska M (2012) 2-acylamino6-pyridones: breaking of an intramolecular hydrogen bond by selfassociation and complexation with double and triple hydrogen bonding counterparts. Uncommon steric effect on intermolecular interactions. J Org Chem 77(4):1653-1662. doi:10.1021/jo201800u

23. Ośmiałowski B, Kolehmainen E, Dobosz R, Gawinecki R, Kauppinen R, Valkonen A, Koivukorpi J, Rissanen K (2010) Self-organization of 2-acylaminopyridines in the solid state and in solution. J Phys Chem A 114(38):10421-10426. doi:10.1021/ jp1063116

24. Ośmiałowski B, Kolehmainen E, Gawinecki R, Dobosz R, Kauppinen R (2010) Complexation of 2,6-Bis(acylamino)pyridines with dipyridin-2-ylamine and 4,4-dimethylpiperidine-2,6-dione. J Phys Chem A 114(49):12881-12887. doi:10.1021/jp1084857

25. Ośmiałowski B, Kolehmainen E, Gawinecki R, Kauppinen R, Koivukorpi J, Valkonen A (2010) NMR and quantum chemical studies on association of 2,6-bis(acylamino)pyridines with selected imides and 2,2'-dipyridylamine. Struct Chem 21:1061-1067. doi:10. 1007/s11224-010-9646-2

26. Lüning U, Kuhl C, Bolte M (2001) N-tert-Butyl-N'-(5,7-dimethyl-1, 8-naphthyridin-2-yl)urea. Acta Cryst C 57(8):989-990. doi:10.1107/ S0108270101008605

27. Corbin PS, Zimmerman SC (1998) Self-association without regard to prototropy. A heterocycle that forms extremely stable quadruply hydrogen-bonded dimers. J Am Chem Soc 120(37):9710-9711. doi:10.1021/ja981884d

28. Kolehmainen E, Ośmiałowski B, Krygowski T, Kauppinen R, Nissinen M, Gawinecki R (2000) Substituent and temperature controlled tautomerism: multinuclear magnetic resonance, X-ray, and 
theoretical studies on 2-phenacylquinolines. J Chem Soc Perkin Trans 6:1259-1266, 2

29. Kolehmainen E, Ośmiałowski B, Nissinen M, Kauppinen R, Gawinecki R (2000) Substituent and temperature controlled tautomerism of 2-phenacylpyridine: the hydrogen bond as a configurational lock of (Z)-2-(2-hydroxy-2-phenylvinyl)pyridine. J Chem Soc Perkin Trans 2(11):2185-2191. doi:10.1039/b006879i

30. Gawinecki R, Kolehmainen E, Loghmani-Khouzani H, Ośmiałowski B, Lovasz T, Rosa P (2006) Effect of pi-electron delocalization on tautomeric equilibria - Benzoannulated 2-phenacylpyridines. Eur J Org Chem 12:2817-2824. doi:10.1002/ejoc.200500840

31. Kuhn B, Mohr P, Stahl M (2010) Intramolecular hydrogen bonding in medicinal chemistry. J Med Chem 53(6):2601-2611. doi:10.1021/ jm100087s

32. Szatyłowicz H, Krygowski T, Palusiak M (2012) Modeling the electronic structure of formamide: an acid/base amphoteric solvent. Struct Chem 23(6):1711-1721. doi:10.1007/s11224-012-9973-6

33. Olivari M, Caltagirone C, Garau A, Isaia F, Light ME, Lippolis V, Montis R, Scorciapino MA (2013) Non-symmetric substituted ureas locked in an (E, Z) conformation: an unusual anion binding via supramolecular assembly. New J Chem 37(3):663-669

34. Kříž J, Dybal J, Makrlík E, Sedláková Z, Kašička V (2013) NMR, FTIR and DFT study of the interaction of the benzoate anion with meso-octamethylcalix[4]pyrrole. Chem Phys Lett 561-562:42-45. doi:10.1016/j.cplett.2013.01.027

35. Szatyłowicz H, Krygowski TM, Fonseca Guerra C, Bickelhaupt FM (2013) Complexes of 4-substituted phenolates with HF and HCN: energy decomposition and electronic structure analyses of hydrogen bonding. J Comput Chem 34(8):696-705. doi:10.1002/jcc.23182

36. Jorgensen WL, Jensen KP, Alexandrova AN (2007) Polarization effects for hydrogen-bonded complexes of substituted phenols with water and chloride Ion. J Chem Theory Comput 3(6):1987-1992. doi:10.1021/ct7001754

37. Krygowski TM, Szatyłowicz H, Zachara JE (2004) How H-bonding affects aromaticity of the ring in variously substituted phenol complexes with bases. 4. Molecular geometry as a source of chemical information. J Chem Inf Comp Sci 44(6):2077-2082. doi:10.1021/ ci049817s

38. Reynisson J, McDonald E (2004) Tuning of hydrogen bond strength using substituents on phenol and aniline: a possible ligand design strategy. J Comput Aided Mol Des 18(6):421-431. doi:10.1007/ s10822-004-3741-7

39. Frisch MJ, Trucks GW, Schlegel HB, Scuseria GE, Robb MA, Cheeseman JR, Scalmani G, Barone V, Mennucci B, Petersson GA, Nakatsuji H, Caricato M, Li X, Hratchian HP, Izmaylov AF, Bloino J, Zheng G, Sonnenberg JL, Hada M, Ehara M, Toyota K, Fukuda R, Hasegawa J, Ishida M, Nakajima T, Honda Y, Kitao O, Nakai H, Vreven T, Montgomery JA Jr, Peralta JE, Ogliaro F, Bearpark M, Heyd JJ, Brothers E, Kudin KN, Staroverov VN, Kobayashi R, Normand J, Raghavachari K, Rendell A, Burant JC, Iyengar SS, Tomasi J, Cossi M, Rega N, Millam JM, Klene M, Knox JE, Cross JB, Bakken V, Adamo C, Jaramillo J, Gomperts R, Stratmann RE, Yazyev O, Austin AJ, Cammi R, Pomelli C, Ochterski JW, Martin RL, Morokuma K, Zakrzewski VG, Voth GA, Salvador P, Dannenberg JJ, Dapprich S, Daniels AD, Farkas O, Foresman JB, Ortiz JV, Cioslowski J, Fox DJ (2009) Gaussian 09, revision a.02. Gaussian 09, revision a.02. Gaussian, Inc, Wallingford

40. Zhao Y, Truhlar DG (2006) Assessment of model chemistries for noncovalent interactions. J Chem Theory Comput 2:1009-1018. doi: $10.1021 / \mathrm{ct} 060044 \mathrm{j}$

41. Zhao Y, Truhlar DG (2008) The M06 suite of density functionals for main group thermochemistry, thermochemical kinetics, noncovalent interactions, excited states, and transition elements: two new functionals and systematic testing of four M06-class functionals and 12 other functionals. Theor Chem Acc 120:215-241. doi:10.1007/s00214-007-0310-x
42. Miertuš S, Scrocco E, Tomasi J (1981) Electrostatic interaction of a solute with a continuum. A direct utilizaion of $\mathrm{AB}$ initio molecular potentials for the prevision of solvent effects. Chem Phys 55(1):117129. doi:10.1016/0301-0104(81)85090-2

43. Biegler-König F, Schönbohm J, Bayles D (2001) AIM2000. J Comp Chem 22(5):545-559. doi:10.1002/1096-987x(20010415) 22:5<545::aid-jcc1027>3.0.co;2-y

44. Boys SF, Bernardi F (1970) The calculation of small molecular interactions by the differences of separate total energies. Some procedures with reduced errors. Mol Phys 19(4):553-566. doi:10.1080/ 00268977000101561

45. Simon S, Duran M, Dannenberg JJ (1996) How does basis set superposition error change the potential surfaces for hydrogenbonded dimers? J Chem Phys 105(24):11024-11031. doi:10.1063/ 1.472902

46. Hansch C, Leo A, Taft RW (1991) A survey of Hammett substituent constants and resonance and field parameters. Chem Rev 91(2):165195. doi:10.1021/cr00002a004

47. Etter MC (1990) Encoding and decoding hydrogen-bond patterns of organic compounds. Acc Chem Res 23(4):120-126. doi:10.1021/ ar00172a005

48. Bader RFW (1990) Atoms in molecules: a quantum theory. Oxford University Press, New York

49. Espinosa E, Molins E, Lecomte C (1998) Hydrogen bond strengths revealed by topological analyses of experimentally observed electron densities. Chem Phys Lett 285(3-4):170-173. doi:10.1016/S00092614(98)00036-0

50. Espinosa E, Souhassou M, Lachekar H, Lecomte C (1999) Topological analysis of the electron density in hydrogen bonds. Acta Cryst B55:563-572. doi:10.1107/S0108768199002128

51. Arunan E, Desiraju GR, Klein RA, Sadlej J, Scheiner S, Alkorta I, Clary DC, Crabtree RH, Dannenberg JJ, Hobza P, Kjaergaard HG, Legon AC, Mennucci B, Nesbitt DJ (2011) Definition of the hydrogen bond (IUPAC recommendations 2011). Pure Appl Chem 83: 1637-1641. doi:10.1351/PAC-REC-10-01-02

52. Jorgensen WL, Pranata J (1990) Importance of secondary interactions in triply hydrogen bonded complexes: guanine-cytosine vs uracil-2,6-diaminopyridine. J Am Chem Soc 112:2008-2010. doi: 10.1021/ja00161a061

53. Hunter CA, Anderson HL (2009) What is cooperativity? Angew Chem Int Ed 48(41):7488-7499. doi:10.1002/anie.200902490

54. Espinosa E, Alkorta I, Elguero J, Molins E (2002) From weak to strong interactions: a comprehensive analysis of the topological and energetic properties of the electron density distribution involving $\mathrm{X}$ H[centered ellipsis]F-Y systems. J Chem Phys 117(12):5529-5542. doi:10.1063/1.1501133

55. Espinosa E, Alkorta I, Rozas I, Elguero J, Molins E (2001) About the evaluation of the local kinetic, potential and total energy densities in closed-shell interactions. Chem Phys Lett 336(5-6):457-461. doi:10. 1016/S0009-2614(01)00178-6

56. Espinosa E, Lecomte C, Molins E (1999) Experimental electron density overlapping in hydrogen bonds: topology vs. energetics. Chem Phys Lett 300(5-6):745-748. doi:10.1016/S0009-2614(98) 01399-2

57. Espinosa E, Molins E (2000) Retrieving interaction potentials from the topology of the electron density distribution: the case of hydrogen bonds. J Chem Phys 113(14):5686-5694. doi:10. $1063 / 1.1290612$

58. Grabowski SJ, Małecka M (2006) Intramolecular H-bonds: DFT and QTAIM studies on 3-(aminomethylene)pyran-2,4-dione and its derivatives. J Phys Chem A 110(42):11847-11854. doi:10.1021/ jp064997p

59. Grabowski SJ (2007) $\pi-\mathrm{H} \cdots \mathrm{O}$ hydrogen bonds: multicenter covalent $\pi-\mathrm{H}$ interaction acts as the proton-donating system. J Phys Chem A 111(51):13537-13543. doi:10.1021/jp076990t 